\title{
Demographic parameters of the indigenous egg parasitoids, Trichogramma spp., parasitizing the invasive tomato leafminer, Tuta absoluta (Meyrick) (Lepidoptera: Gelechiidae)
}

\author{
T. N. Manohar, P. L. Sharma*, S. C. Verma and R. S. Chandel
}

\begin{abstract}
Tuta absoluta (Meyrick) (Lepidoptera: Gelechiidae), one of the most destructive pests of tomato, has recently invaded India. Before recommending any bio-control agent for its control, it is important to study the demographic parameters of the bio-agent on the pest. The present study evaluates the demographic parameters of indigenous trichogrammatids namely Trichogramma achaeae Nagaraja and Nagarkatti, T. pretiosum Riley, T. chilonis (Ishii), and T. pieridis Nagaraja and Prashanth against this pest, aiming to select the most effective egg parasitoid species. Significant differences were observed among the demographic parameters of different Trichogramma spp. Parasitization potential of a thelytokous strain of T. pretiosum was the highest, followed by T. achaeae, T. chilonis, and T. pieridis. Population growth parameters net reproductive rate, intrinsic rate of natural increase, finite rate of increase, and weekly multiplication rate were highest, and generation time and doubling period were shortest for $T$. pretiosum, followed by T. achaeae, T. chilonis, and T. pieridis. The study concluded that T. pretiosum could be considered a potential candidate for biological control of T. absoluta; however, field evaluation is required before final recommendation.
\end{abstract}

Keywords: Trichogramma spp., Tuta absoluta, Intrinsic rate of increase, Life-fertility table, Parasitism, Population parameters

\section{Background}

Outside its native home, Tuta absoluta (Meyrick) (Lepidoptera: Gelechiidae) was detected for the first time in Spain in 2006 (Urbaneja et al. 2008), and since then, it has invaded many countries including India (CABI 2018). At present, the pest has spread to almost all the tomato growing parts of India (Sridhar et al. 2014; Ballal et al. 2016 and Sharma and Gavkare 2017). The larvae cause damage by mining into the leaves, shoots, flowers, buds, and fruits (Sharma and Gavkare 2017). Previous reports indicate that in newly invaded areas, the pest immediately attained the status of a serious pest of tomato causing $100 \%$ crop damage in the absence of control

\footnotetext{
* Correspondence: sharma.pl@rediffmail.com

Department of Entomology, YSP University of Horticulture and Forestry, Nauni, Solan, Himachal Pradesh 173 230, India
}

measures (Arturo et al. 2012 and Ballal et al. 2016). The pest is extremely difficult to control with insecticides, and sometimes, as high as 14 rounds of sprays in a growing season were required (Luna et al. 2012). It is, therefore, important to develop sustainable, costeffective, and eco-friendly alternative management strategies for this pest. Biological control based on the use of trichogrammatids can, therefore, be a viable option (van Lenteren 2012). The possible use of Trichogramma spp. as biological control agents of T. absoluta is currently considered all over the world because of the natural parasitism on the pest by different Trichogramma species (Zappala et al. 2012 and Goda et al. 2015). The effectiveness of a bio-control agent is directly related to its fitness. Survival, fecundity, and development time are the most important parameters that determine the 
fitness of a natural enemy. The successful use of Trichogramma spp. in biological control depends on knowledge of their biotic potential against the target pest and the thermal requirements (Coelho et al. 2016). Different Trichogramma species and/or strains differ in their efficiency against the target pest, thus, making it necessary to study the performance of different species/strains of Trichogramma on the target pest (Bueno et al. 2009). Implementation of the Nagoya protocol on access to genetic resources and the fair and equitable sharing of benefits under the convention of biological diversity impose restrictions on the importation and release of the effective strains outside their area of origin. Due to these reasons, it is necessary to evaluate first the indigenous species/strains of natural enemies against the invasive pests. In the preliminary evaluation, it is important to study the population growth parameters, especially the intrinsic rate of increase, because not only it does directly represent their biotic potential, but also it determines the releasing strategy (i.e., inoculative, seasonal inoculative, or inundative) (van Lenteren 1986) and compares hosts (Iranipour et al. 2009). Parasitism rate, emergence rate, longevity, developmental time, total fecundity, and sex ratio are the other biological parameters used to evaluate the performance of natural enemies against pests (El-Wakeil 2007).

The present study comprises, therefore, attempts to study the biological and population growth parameters of indigenous trichogrammatids against the invasive tomato leafminer, T. absoluta, in order to select the most effective species and/or strain that can be used successfully to control the pest in tomato cultivations

\section{Materials and methods Insect cultures Tuta absoluta}

Stock culture of T. absoluta was raised in the laboratory from field collected larvae on tomato leaves in insect rearing cages $(45 \times 45 \times 45 \mathrm{~cm})$ fitted with glass on three sides and nylon net on the front side. Larval food was changed daily or on alternate days depending upon the requirement until larvae reached the pupal stage. Obtained pupae were kept in glass tubes until adults' emergence. Newly emerged adults were transferred to insect rearing cages to allow mating and were provided by $30 \%$ honey solution (in cotton swabs) as food and fresh tomato leaves (petioles immersed in water in plastic tubes) as a substrate for oviposition. Two days after exposure, the leaves having $T$. absoluta eggs were transferred to another cage and observed until hatching. The neonate larvae were carefully transferred by the aid of a fine camel hairbrush to fresh tomato leaves and reared as described above. T. absoluta was reared and multiplied for two generations to have sufficient culture for experiments.

\section{Trichogramma spp.}

Nucleus cultures of the indigenous trichogrammatids $T$. achaeae, T. pretiosum (thelytokous strain), T. chilonis, and $T$. pieridis were obtained from the Bio-Control Research Laboratory of the Department of Entomology, Dr. Y S Parmar, University of Horticulture and Forestry, Nauni, Solan (HP), India. Each Trichogramma species was further raised separately on the eggs of $T$. absoluta in the laboratory. Freshly laid eggs of T. absoluta on tomato leaves, after UV eradiation for $45 \mathrm{~min}$, were exposed to respective Trichogramma species for $24 \mathrm{~h}$ in a glass tube for parasitism. After $24 \mathrm{~h}$, the eggs were transferred to another glass tube and observed daily for the emergence of the parasitoid adults. The emerged adults were kept for mating and provided with 30\% honey streaked on the side wall of the tube for feeding. Each Trichogramma species was reared for one generation before being used in experiments. The environmental conditions used for raising the cultures and conducting the experiments were $25 \pm 0.5^{\circ} \mathrm{C}, 70 \pm 5 \% \mathrm{RH}$, and $12 \mathrm{~L}: 12 \mathrm{D}$ photoperiod.

\section{Developmental biology}

Developmental biology of each species was studied on $T$. absoluta eggs under laboratory conditions. For this purpose, 12-h-old adults of each species were sexed and every couple was offered $30 \mathrm{~T}$. absoluta eggs on a tomato leaflet in a glass tube in a no-choice experiment. After $24 \mathrm{~h}$, the eggs were transferred to another tube and observed daily for parasitism and emergence of the parasitoid adults. Every set was replicated ten times. After $24 \mathrm{~h}$ exposure, the exposed eggs for parasitism were replaced by other new fresh 30 eggs of the host. Exposure and replacement of eggs was repeated until all the parasitoids' adults died. The parasitized eggs were carefully reared as described earlier. Host eggs, which hatched normally, were the unparasitized, while those which turned black and failed to hatch were considered as parasitized. As the immature stages of the parasitoid species completed their development, the period from starting exposure of the host eggs until parasitoid adult's emergence was recorded as egg-adult emergence period. Observations on the duration of egg to adult emergence, adult longevity, percent of adults' emergence, parasitization percent, sex ratio, and fecundity (host parasitism basis) were recorded. The data were subjected to one-way analysis of variance (ANOVA) after appropriate transformation through an online software OP-STAT available at http://www.hu.ernet.in. (Sheoran et al. 1998), and significantly different means were separated by least significant difference (LSD) or critical difference (CD) at $p=0.05$. 


\section{Population growth parameters}

Fertility tables were constructed to study the population growth parameters of each Trichogramma species reared on T. absoluta eggs. For this purpose, one pair (10 replicates) of newly emerged adults was offered with 30 host eggs on tomato leaflet in a glass tube. After $24 \mathrm{~h}$, the host eggs were removed and kept for the emergence of the parasitoid's adults. Obtained adults were sexed under a microscope and every single pair was offered 30 eggs of the host. After $24 \mathrm{~h}$, the old batch of eggs was replaced by a new fresh healthy batch and the process was continued until the last parasitoid adult died. The host eggs were kept separately until the emergence of adults. The host eggs, which turned black and failed to hatch, were considered as parasitized and counted for the fecundity of the parasitoids. Daily survival and fecundity data were used to construct life-fertility tables of each parasitoid on the host separately to calculate the population growth parameters as follows:

$x=$ Age of the individuals in days (pivotal age), $\mathrm{l}_{x}=$ the proportion of females still alive at age $x$ (survival rate), and $m_{x}=$ the number of female eggs laid per female at the age $x$ (fecundity rate). Data thus obtained were used to calculate the following population growth parameters or fertility parameters:

i. The net reproductive rate $\left(R_{\mathrm{o}}\right)$ : rate of multiplication of the population in each generation, measured in terms of females produced per generation, calculated as $R_{o}=\Sigma \mathrm{l}_{x} m_{x}$ (females produced/female)

ii. Intrinsic rate of natural increase $(\mathrm{rm})$ : intrinsic rate of increase $(\mathrm{rm})$ was calculated by using the expression $\Sigma\left(e^{-\mathrm{rmx}} 1_{x} m_{x}\right)=1$

iii. Mean generation time $(T)$ : the mean period elapsing from the birth of parents to the birth of offspring, calculated by the formula $T=\log _{e} R_{o} / \mathrm{rm}$

iv. Finite rate of natural increase $(\lambda)$ : the number of times the population increases per unit time, calculated by the formula: $\lambda=$ Antilog $_{e} \mathrm{rm}$.

v. The weekly multiplication rate: number of times the population increases in a week, calculated by the formula $(\mathrm{WE})=e^{7 \mathrm{r} m}$.

vi. The doubling time (DT): the time taken in days by a species to double its population, calculated by the formula DT $=\log _{e} 2 / \mathrm{rm}$

The jack-knife procedure was used to recalculate the above parameters. The jack-knife method removes one observation from the original data set and recalculates the parameter of interest from the truncated data set.
These new estimates, also called as pseudovalues, were further used to calculate the fresh values of each parameter, which serve as replications for the parameter to calculate mean and variances (Maia et al. 2000).

\section{Data analysis}

Data on the survival, development, fecundity, and population growth parameters of the pest on different hosts were subjected to one-way analysis of variance through an online software OP-STAT available at http:// www.hau.ernet.in. (Sheoran et al. 1998), and significantly different means were separated by least significant difference (LSD) or critical difference (CD) at $p=0.05$.

\section{Results and discussion Developmental biology}

Trichogramma spp. under study differed significantly in their efficacy to parasitize T. absoluta eggs. Highest parasitism $(84.22 \%)$ was resulted by $T$. pretiosum, followed by T. achaeae (73.78\%), T. chilonis (70.33\%), and T. pieridis (62.56\%). T. achaeae and T. chilonis showed the same efficacy, but both were superior to $T$. pieridis and inferior to T. pretiosum in parasitizing the host eggs. The developmental time from the egg until adult emergence varied from 10.5 to 10.8 days, with insignificant difference among species. Percentage of adults' emergence was also highest $(89.16 \%)$ in $T$. pretiosum, being almost on par with T. achaeae (88.83\%), while the minimum occurred in $T$. pieridis $(82.75 \%)$ (Table 1). Female longevity (4.17 days) was also longer in T. pretiosum than other species (3.5 to 3.53 days). Similarly, the females of $T$. achaeae and $T$. pretiosum were more fecund (55.9 and 54.75 eggs/female, respectively) than $T$. chilonis (51.44 eggs/female) and $T$. pieridis (41.48 eggs/female). In the four species under study, females lived longer than males and the sex ratio was female-biased varying from 1:1.48 (male to female) in $T$. peiridis to 0:1 in T. pretiosum.

Among the four trichogrammatid species, $T$. pretiosum had the best biological and population growth parameters on T. absoluta than the remaining three species. However, $T$. achaeae was able to match $T$. pretiosum with respect to the percentage of adult emergence and fecundity. Host parasitism by different egg parasitoids (62.56-84.22\%), obtained in the present study, was close to $(65.9-91.74 \%)$ that recorded by previous authors who studied the percentages of parasitism by different Trichogramma spp. against different hosts (Chailleux et al. 2012 and Cabello et al. 2012). Adults' emergence from the parasitized host eggs was more than $80 \%$ in each case, which is not so far from the findings of Ballal et al. (2016) who reported 91.01 to $97.5 \%$ adult emergence in $T$. pretiosum parasitizing $T$. absoluta. Immature developmental period appears not to show much variation (9- 
Table 1 Biological parameters of Trichogramma spp. (second generation) on Tuta absoluta eggs in tomato

\begin{tabular}{|c|c|c|c|c|c|c|}
\hline \multirow{2}{*}{\multicolumn{2}{|c|}{ Parameter }} & \multicolumn{4}{|c|}{ Parameter estimate (mean \pm SE) of Trichogramma species } & \multirow{2}{*}{$\begin{array}{l}C D \\
(p= \\
0.05)\end{array}$} \\
\hline & & T. achaeae & T. pretiosum & T. chilonis & T. pieridis & \\
\hline \multicolumn{2}{|c|}{$\begin{array}{l}\text { Duration of eggs to adult } \\
\text { emergence (days) }\end{array}$} & $10.80 \pm 0.20$ & $10.70 \pm 0.26$ & $10.50 \pm 0.16$ & $10.70 \pm 0.26$ & NS \\
\hline \multicolumn{2}{|c|}{$\begin{array}{l}\text { Number of eggs parasitized/ } \\
30 \text { eggs }\end{array}$} & $22.13^{b} \pm 0.37$ & $25.67^{a} \pm 0.28$ & $21.10^{\mathrm{b}} \pm 0.49$ & $18.77^{c} \pm 0.98$ & 1.79 \\
\hline \multicolumn{2}{|c|}{ Parasitization (\%) ${ }^{d}$} & $\begin{array}{l}73.78 \pm 1.17\left(59.23^{b} \pm\right. \\
0.81)\end{array}$ & $\begin{array}{l}84.22 \pm 0.87\left(66.65^{\mathrm{a}} \pm\right. \\
0.73)\end{array}$ & $\begin{array}{l}70.33 \pm 1.62\left(57.05^{b} \pm\right. \\
1.06)\end{array}$ & $\begin{array}{l}62.56 \pm 3.27\left(52.42^{\mathrm{C}} \pm\right. \\
2.07)\end{array}$ & $(3.40)$ \\
\hline \multicolumn{2}{|c|}{ Number of adults emerged } & $19.50^{\mathrm{a}} \pm 0.23$ & $22.53^{\mathrm{a}} \pm 0.31$ & $17.73^{\mathrm{C}} \pm 0.44$ & $15.47^{d} \pm 0.77$ & 1.41 \\
\hline \multicolumn{2}{|c|}{ Adult emergence (\%) ${ }^{e}$} & $88.83 \pm 1.02\left(9.45^{\mathrm{ab}} \pm 0.06\right)$ & $89.16 \pm 0.79\left(9.50^{a} \pm 0.04\right)$ & $84.18 \pm 1.87\left(9.22^{b c} \pm 0.10\right)$ & $82.75 \pm 1.97\left(9.14^{c} \pm 0.11\right)$ & $(0.24)$ \\
\hline \multirow{2}{*}{$\begin{array}{l}\text { Adult longevity } \\
\text { (days) }\end{array}$} & Male & $2.06 \pm 0.15$ & - & $1.94 \pm 0.06$ & $2.01 \pm 0.08$ & NS \\
\hline & Female & $3.50^{\mathrm{b}} \pm 0.13$ & $4.17^{a} \pm 0.09$ & $3.53^{b} \pm 0.13$ & $3.53^{b} \pm 0.09$ & 0.33 \\
\hline \multicolumn{2}{|l|}{ Fecundity } & $55.90^{\mathrm{a}} \pm 0.59$ & $54.75^{\mathrm{a}} \pm 0.72$ & $51.44^{b} \pm 0.57$ & $41.48^{\complement} \pm 0.94$ & 2.08 \\
\hline \multicolumn{2}{|l|}{ Male $(\%)^{d}$} & $\begin{array}{l}37.63 \pm 1.39\left(37.63^{b} \pm\right. \\
0.87)\end{array}$ & $0.00 \pm 0.00(0.00 \pm 0.00)$ & $\begin{array}{l}36.65 \pm 1.62\left(37.20^{\mathrm{b}} \pm\right. \\
1.02)\end{array}$ & $\begin{array}{l}40.35 \pm 1.66\left(39.38^{\mathrm{a}} \pm\right. \\
1.03)\end{array}$ & $(2.34)$ \\
\hline \multicolumn{2}{|l|}{ Female $(\%)^{d}$} & $62.64 \pm 1.39\left(52.33^{\mathrm{a}} \pm 0.87\right)$ & $100 \pm 0.00\left(90.00^{\mathrm{a}} \pm 0.00\right)$ & $\begin{array}{l}63.35 \pm 1.62\left(52.77^{\mathrm{b}} \pm\right. \\
1.02)\end{array}$ & $\begin{array}{l}59.65 \pm 1.66\left(50.58^{\mathrm{C}} \pm\right. \\
1.03)\end{array}$ & $(2.43$ \\
\hline \multicolumn{2}{|l|}{ Sex ratio ( $M$ to $F$ ) } & $1: 1.68$ & $0: 1$ & $1: 1.73$ & $1: 1.48$ & - \\
\hline
\end{tabular}

$a, b, c$ Mean values followed by same alphabet in a row do not differ significantly at $p=0.05$

${ }^{\mathrm{d}}$ Figures in parentheses are arc sine transformed values

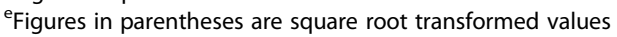

10.8 days) with the egg parasitoid or the host insect, when reared at $25^{\circ} \mathrm{C}$ (Bueno et al. 2010; Perveen et al. 2012 and Krechemer and Foerster 2015). Female longevity, however, varied with both the parasitoid and the host species. Female's longevity of $T$. pretiosum (4.17 days) was longer on T. absoluta (present study) than that recorded on T. $n i$ (2 days) (Bueno et al. 2010). Female longevity of $T$. chilonis on $T$. absoluta (3.53 days), recorded in the present study, was shorter than recorded on eggs of $S$. cerealella (4.3 days) (Perveen et al. 2012), Corcyra cephalonica (3.76-5.6 days) (Perveen et al. 2012 and Vigneswaran et al. 2017), and $H$. armigera (6.7 days) (Puneeth and Vijayan 2014). The present study confirmed a longer longevity for females than males; this finding agrees with Puneeth and Vijayan (2014) who reported the same phenomenon in $T$. chilonis on $H$. armigera. The fecundity of Trichogramma spp. under study varied from 41.48 to 55.9 eggs/female. Eggs reproductively of $T$. pretiosum (54.75 eggs/female) on $T$. absoluta recorded in the present study was almost the same (59.82 eggs/female) as that previously recorded by Pratissoli and Parra (2000) for this species on the same host. The fecundity of T. pretiosum on T. absoluta was, however, much higher than that recorded for T. ostrinae on O. nubilalis (22.4 eggs/female) (Hoffmann et al. 1995). The present study assured a female-biased sex ratio in all the tested Trichogramma spp. and confirmed the earlier reports where a female skewed sex ratio was found in $T$. pretiosum and T. chilonis on different hosts (Bueno et al. 2010 and Krechemer and Foerster 2015).

\section{Population growth parameters}

Survival up to adults' emergence was highest (87\%) for $T$. pieridis, followed by $T$. pretiosum, T. chilonis (82\%), and T. achaeae (73\%), which occurred on the 11th day of the pivotal age in each species (Fig. 1). Thereafter, the survival rate decreased gradually and all the parasitoids' adults died on the 15th, 17th, 16th, and 16th day of the pivotal age in $T$. achaeae, $T$. pretiosum, $T$. chilonis, and T. pieridis, respectively. As for the age-specific fecundity, all the Trichogramma species started ovipositing on the first day after adult's emergence and continued for the next 5 days (Fig. 2). All the egg parasitoid species achieved their highest daily fecundity on the 12th day of the pivotal age, being 13.86, 17.32, 12.70, and 10.78 female eggs/female for $T$. achaeae, $T$. pretiosum, $T$. chilonis, and $T$. pieridis, respectively. Population growth parameters, except true generation time, varied significantly among species (GRR: $F_{3,36}=253.04, p<0.001 ; R_{o}$ : $F_{3,36}=905.7, p<0.001$; Tc: $F_{3,36}=2.91, p=0.048$; rc: $F_{33}$, ${ }_{36}=128.85, p<0.001 ; \mathrm{rm}: F_{3}, 36=82.49, p<0.001 ; \mathrm{T}$ : $F_{3.36}=0.88, p=0.462 ; \lambda: F_{3,36}=12.24, p<0.001 ; \mathrm{DT}: F_{3}$, $\left.{ }_{36}=55.93, p<0.001 ; \quad \mathrm{WM}: F_{3}, 36=105.71, p<0.001\right)$ (Table 2). Gross reproductive rate (GRR), net reproductive rate $\left(R_{o}\right)$, innate capacity for natural increase $(\mathrm{rc})$, true intrinsic rate of increase $(\mathrm{rm})$, finite rate of natural increase $(\lambda)$, and weekly multiplication rate (WM) were highest, and doubling time (DT) was lowest for T. pretiosum, followed by T. achaeae, T. chilonis, and T. pieridis, indicating that $T$. pretiosum had the ability to grow faster than the rest of species, while foraging against $T$. 


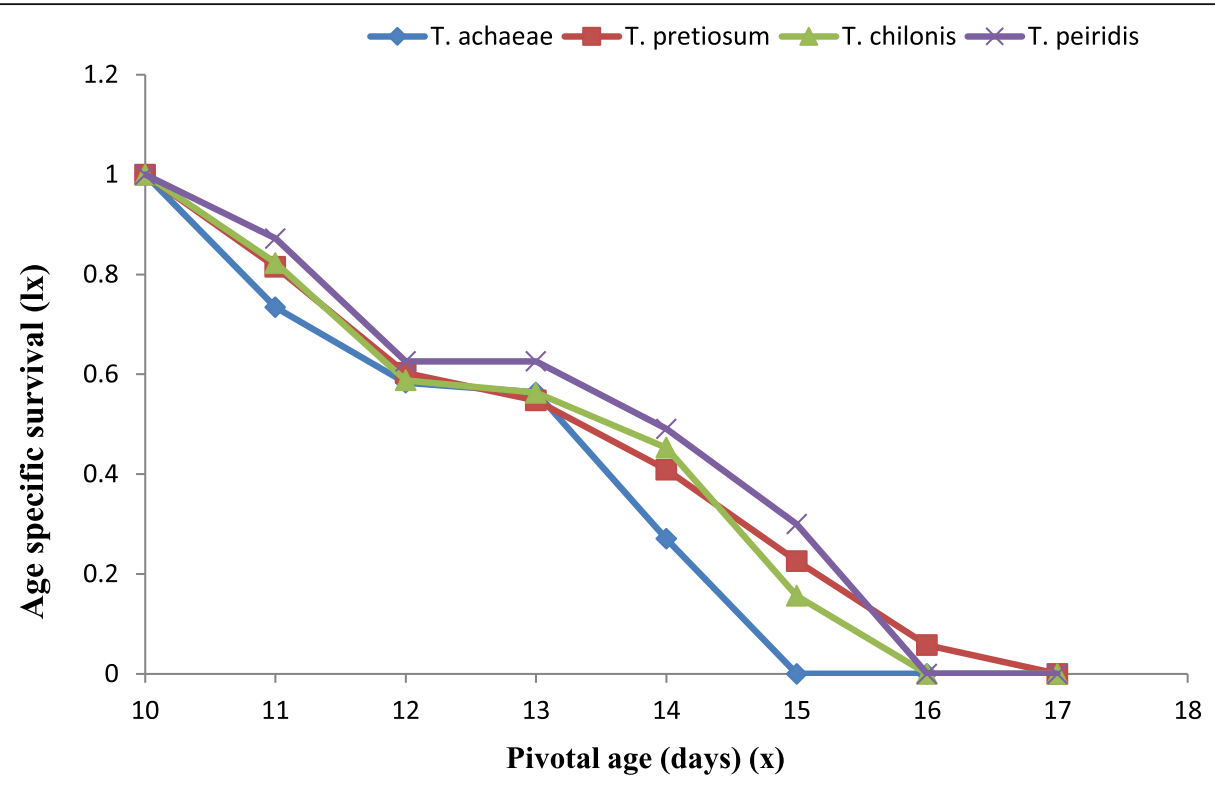

Fig. 1 Comparison of age-specific survival (Ix) of Trichogramma spp. on Tuta absoluta

absoluta eggs in tomato. The higher population growth of $T$. pretiosum could be attributed to the fact that the strain of this species used in the study was a thelytokous one, where all individuals contribute towards the population growth. Among the arrhenotokous species, $T$. achaeae had slightly better population growth parameters than $T$. chilonis, whereas $T$. pieridis was the poorest among all. Net reproductive rate $\left(R_{o}\right)$ and intrinsic rate of increase $(\mathrm{rm})$ were maximum (30.61 females/female and 0.3285 females/female/day) for $T$. pretiosum, followed by $T$. achaeae (20.62 females/female and 0.2390 females/female/day), T. chilonis (18.03 females/female and 0.2292 females/female/day), and T. pieridis (14.9 females/female and 0.2228 females/female/day), respectively. Different Trichogramma spp. under study did not vary significantly with respect to their generation time (12.14 to 12.61 days). Like other population growth parameters, the finite rate of increase was highest (1.39 females/day) for $T$. pretiosum, followed by $T$. achaeae (1.29), T. chilonis (1.26), and lastly T. pieridis (1.2). T.

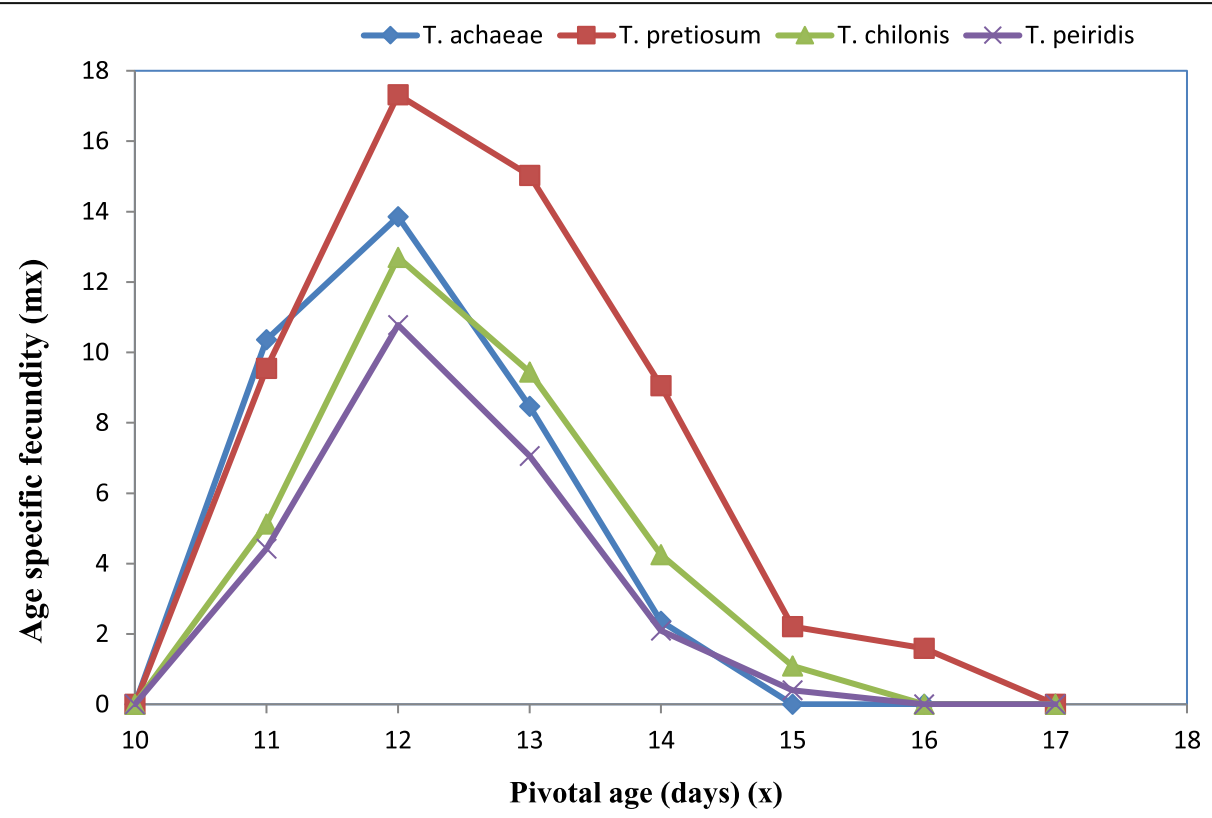

Fig. 2 Comparison of age-specific fecundity $(m x)$ of Trichogramma spp. on Tuta absoluta 
Table 2 Comparison of population growth parameters of Trichogramma spp. parasitizing Tuta absoluta in tomato

\begin{tabular}{|c|c|c|c|c|c|c|c|c|c|}
\hline \multirow{2}{*}{$\begin{array}{l}\text { Trichogramma } \\
\text { sp. }\end{array}$} & \multicolumn{9}{|c|}{ Population growth parameters (mean \pm SE) } \\
\hline & GRR & Ro & Tc & rc & $\mathrm{rm}$ & T & $\lambda$ & DT & WM \\
\hline T. achaeae & $35.03^{b} \pm 1.04$ & $20.62^{b} \pm 0.58$ & $11.97^{b} \pm 0.14$ & $0.2549^{b} \pm 0.004$ & $0.2390^{b} \pm 0.004$ & $12.61 \pm 0.15$ & $1.29^{b} \pm 0.02$ & $2.89^{\mathrm{a}} \pm 0.04$ & $5.29^{b} \pm 0.17$ \\
\hline T. pretiosum & $54.75^{\mathrm{a}} \pm 1.60$ & $30.61^{\mathrm{a}} \pm 1.60$ & $12.64^{\mathrm{a}} \pm 0.24$ & $0.3275^{a} \pm 0.005$ & $0.3285^{\mathrm{a}} \pm 0.005$ & $12.61 \pm 0.23$ & $1.39^{\mathrm{a}} \pm 0.007$ & $2.06^{b} \pm 0.05$ & $9.46^{\mathrm{a}} \pm 0.27$ \\
\hline T. chilonis & $32.60^{b} \pm 1.43$ & $18.03^{c} \pm 0.44$ & $12.66^{\mathrm{a}} \pm 0.12$ & $0.2283^{c} \pm 0.004$ & $0.2292^{b} \pm 0.004$ & $12.60 \pm 0.19$ & $1.26^{b} \pm 0.004$ & $3.02^{\mathrm{a}} \pm 0.04$ & $4.96^{b} \pm 0.14$ \\
\hline T. pieridis & $24.76^{c} \pm 0.80$ & $14.9^{d} \pm 0.56$ & $12.51^{\mathrm{ab}} \pm 0.16$ & $0.2159^{d} \pm 0.005$ & $0.2228^{\mathrm{b}} \pm 0.008$ & $12.14 \pm 0.37$ & $1.20^{c} \pm 0.04$ & $3.10^{\mathrm{a}} \pm 0.11$ & $4.74^{b} \pm 0.27$ \\
\hline$C D(p=0.05)$ & 3.63 & 1.69 & 0.54 & 0.0130 & 0.0160 & NS & 0.067 & 0.19 & 0.63 \\
\hline
\end{tabular}

${ }^{a, b, c, d}$ Mean values followed by same alphabet in a column do not differ significantly at $p=0.05$

pretiosum had the capacity to double its population in (2.06 days) with weekly multiplication rate of $(9.46$ times). T. achaeae, T. chilonis, and T. pieridis, on the other hand, required $2.89,3.02$, and 3.10 days to double their populations with weekly multiplication rates of 5.29-, 4.96-, and 4.76-folds, respectively.

Selection of a quality bio-control agent is crucial for any successful bio-control program. Quality of a bio-control agent is generally assessed by its survival rate, fecundity, generation time, sex ratio, multiplication rate, etc. Fertility tables summarize the information on the biological performance of the species taking into consideration the age-specific survival and fecundity of the species to determine the net reproductive rate $\left(R_{o}\right)$ and intrinsic rate of natural increase $(\mathrm{rm})$. The intrinsic rate of natural increase is a measure of the biotic potential of the species. It integrates the effect of the fertility factors into a single value. Hence, this parameter can be used as a single parameter instead of comparing several life history parameters, e.g., development rate, longevity, fecundity, and sex ratio (Havelka and Zemek 1999). The intrinsic rate of increase can be also used to determine the finite rate of increase $(\lambda)$, which depicts the number of times the population increases per unit time in a generation. Population growth parameters such as intrinsic rate of increase, net reproductive rate, and finite rate of increase are influenced by nature and quality of the host (Qiu et al. 2013).

Data of the present study reports that the net reproductive rate, intrinsic rate of increase, finite rate of increase, and weekly multiplication rate were highest, and generation time and doubling time were the lowest for $T$. pretiosum, followed by $T$. achaeae, $T$. chilonis, and $T$. pieridis, indicating the highest population growth for $T$. pretiosum. The reason for the higher population growth of $T$. pretiosum could be attributed to the fact that the strain used of this species in the present study was a thelytokous one where all individuals contribute towards the population growth. Among arrhenotokous species, $T$. achaeae had slightly better population growth parameters than $T$. chilonis, whereas, $T$. pieridis was the poorest among all. The gross reproductive rate and net reproductive rate of different egg parasitoid species, reported in the present study, falls within the range reported by (Pratissoli et al. 2004a, b and Iranipour et al. 2009) for different Trichogramma spp. on different host species.

The intrinsic rate of increase, also called as the specific growth rate, was also the maximum (0.3285 females/female/day) for $T$. pretiosum, followed by $T$. achaeae (0.2390 females/female/day), T. chilonis (0.2292 females/ female/day), and T. pieridis (0.2228 females/female/day), respectively. The intrinsic rate of increase of $T$. pretiosum, recorded in the present study, is not so far from those recorded by Pratissoli and Parra (2000) and Pratissoli et al. (2004a) for the same Trichogramma sp. on $T$. absoluta and S. cerealella eggs (0.31 and 0.299 females/ female/day, respectively). The generation time for all the species under study (12.14-12.61 days) agree with the findings of Pratissoli and Parra (2000) and Pratissoli et al. (2004a) (13.32 and 11.74 days) for T. pretiosum on $T$. absoluta and S. cerealella eggs, respectively. Like other population growth parameters, finite rate of increase was also highest 1.39 (females/day) for T. pretiosum, followed by $T$. achaeae (1.29), T. chilonis (1.26), and T. pieridis (1.2). Earlier, Pratissoli and Parra (2000) reported that $T$. pretiosum had a finite rate of increase of $1.349 \mathrm{fe}$ males/day on T. absoluta eggs, which is very close to that obtained in the present study. T. pretiosum had the capacity to double its population in (2.06 days) with weekly multiplication rate of 9.46 times. $T$. achaeae, $T$. chilonis, and T. peiridis, on the other hand, required $2.89,3.02$, and 3.10 days to double their populations with weekly multiplication rates of 5.29-, 4.96-, and 4.76-folds, respectively. All these species required a slightly longer time to double their population than $T$. cacoeciae on Cadra cautella (1.26 to 1.28 days) (Ozder and Kara 2010).

The present study reports significant variations in the population growth parameters of different Trichogramma species under study. Interspecific variations about the population growth parameters in Trichogramma spp. have also been reported in earlier studies (Pratissoli and Parra 2000; Pratissoli et al. 2004a, b; Ozder and Kara 2010). Population growth parameters also varied with the host and the net reproductive rate 
$\left(R_{o}\right)$, the intrinsic rate of increase $(\mathrm{rm})$, the finite rate of increase $(\lambda)$, and the mean generation time $(\mathrm{T})$ of $T$. pretiosum on S. cerealella eggs at $25^{\circ} \mathrm{C}$ was $34.05,0.299$, 1.349, and 11.74, respectively (Pratissoli et al. 2004a). Rearing temperature is another important factor that can significantly affect the population parameters. Fertility life table of $T$. pretiosum and T. acacioi on A. kuheniella showed an inverse relationship between the generation time $(T)$ and temperature. When temperature increased from 15 to $35^{\circ} \mathrm{C}$, the generation time of $T$. pretiosum and T. acacioi decreased from 49.76 to 7.54 and 50.66 to 7.55 days, respectively (Pratissoli et al. 2004b). The gross reproductive rate of these species varied from 13.98 to 54.97 and 9.36 to 62.89 with a maximum value achieved at 30 and $20^{\circ} \mathrm{C}$, respectively. The true intrinsic rate and the finite rate of natural increase of $T$. pretiosum and T. acacioi increased between 15 and $30{ }^{\circ} \mathrm{C}$ and 25 and $30^{\circ} \mathrm{C}$, respectively (Pratissoli et al. 2004b). Similarly, the doubling time of Trichogramma cacoeciae on Cadra cautella noted at 25 and $30^{\circ} \mathrm{C}$ was 1.28 and 1.26, respectively (Ozder and Kara 2010). Among different physical factors, the temperature was reported to have the strongest influence on the biological characteristics of Trichogramma by Noldus (1989) and Pratissoli (1995). On the basis of the present and previous studies, it could be inferred that different species of Trichogramma vary in population parameters impacted by rearing temperature and the host insect.

\section{Conclusion}

Among the evaluated Trichogramma species, the thelytokous strain of $T$. pretiosum exhibited better biological and population growth parameters against $T$. absoluta and can be a potential candidate for inundative releases against the pest. However, further studies on field evaluation of the parasitoid against the pest are required before recommending the parasitoid for biological control of the pest.

\section{Acknowledgements}

The authors are thankful to Indian Council of Agricultural Research, New Delhi, India for providing funds needed for the achievement of this work through All India Coordinated Research Project on Biological Control of Crop Pests and Weeds.

\section{Funding}

Funding is by Indian Council of Agricultural Research, New Delhi, India.

\section{Availability of data and materials}

Not applicable

\section{Authors' contributions}

PL planned the research and designed the methodology. TN conducted the experiments. SC helped in the data analysis. RS drafted the manuscript. All the authors have read and approved the final manuscript.

Ethics approval and consent to participate Not applicable
Consent for publication

Not applicable

\section{Competing interests}

The authors declare that they have no competing interests.

\section{Publisher's Note}

Springer Nature remains neutral with regard to jurisdictional claims in published maps and institutional affiliations.

Received: 7 September 2018 Accepted: 8 February 2019

Published online: 22 February 2019

\section{References}

Arturo C, Salvatore D, Gavino D (2012) Integrated control in protected crops. Med Climate Int Org Biol Int Cont-West Palaearctic Reg Sec Bull 80:319-324

Ballal CR, Gupta A, Mohan M, Lalitha Y, Verghese A (2016) The new invasive pest Tuta absoluta (Meyrick) (Lepidoptera: Gelechiidae) in India and its natural enemies along with evaluation of trichogrammatidsfor its biological control. Curr Sci 110:2155-2159

Bueno RCO, Bueno ADF, Parra JRP, Vieira SS, Oliveira LJ (2010) Biological characteristics and parasitism capacity of Trichogrammapretiosum Riley (Hymenoptera, Trichogrammatidae) on eggs of Spodoptera frugiperda (J. E. Smith) (Lepidoptera, Noctuidae). Rev Brasileira de Entomol 54:322-327

Bueno RCOF, Parra JRP, Bueno AF, Haddad ML (2009) Desempenho de tricogramatíd eoscomopotenciaisagentes de controle de Pseudoplusiaincludens Walker (Lepidoptera: Noctuidae). Neot Entomol 38: 389-394

Cabello T, Gallego JR, Fernandez FJ, Gamez M, Vila E, Pino M, Hernandez-Suarez E (2012) Biological control strategies for the South American tomato moth (Lepidoptera: Gelechiidae) in greenhouse tomatoes. J Econ Entomol 105: 2085-2096

CABI (2018) Tuta absoluta. In: Invasive species compendium. CAB International, Wallingford www.cabi.org/isc. [Accessed on 24 Nov 2018

Chailleux A, Desneux N, Seguret N, Khanh H, Maignet P, Tabone E (2012) AssessingEuropean egg parasitoids as a mean of controlling the invasive South American tomato pinworm Tuta absoluta. J Pub Lib Sci 7:1-7

Coelho A, Rugman-Jones PF, Reigada C, Stouthamer R, Parra JRP (2016) Laboratory performance predicts the success of field releases in inbred lines of the egg parasitoid Trichogramma pretiosum (Hymenoptera: Trichogrammatidae). PLoS One 11:e0146153. https://doi.org/10.1371/journal. pone. 0146153

El-Wakeil NE (2007) Evaluation of efficiency of Trichogramma evanescens reared on different factitious hosts to control Helicoverpa armigera. J Pest Sci 80:29-34

Goda NF, El-Heneidy AH, Djelouah K, Hassan N (2015) Integrated pest management of the tomato leaf miner, Tuta absoluta (Meyrick) (Lepidoptera: Gelechiidae) in tomato fields in Egypt. Egypt J Biol Pest Cont 25(3):655-661

Havelka DJ, Zemek R (1999) Life table parameters and oviposition dynamics of various population of the predacious gall-midge Aphidioletes aphidimyz. Entomol Exp Appl 91:481-484

Hoffmann MP, Walker DL, Shelton AM (1995) Biology of Trichogramma ostriniae (Hym.: Trichogrammatidae) reared on Ostrinia nubilalis (Lep.: Pyralidae) and survey for additional hosts. Entomophaga 40:387-402

Iranipour S, Farazmand A, Saber M, Mashhadi JM (2009) Demography and life history of the egg parasitoid, Trichogramma brassicae, on two moths Anagasta kuehniella and Plodia interpunctella in the laboratory. J Insect Sci 9:1-8

Krechemer FS, Foerster JA (2015) Temperature effects on the development and reproduction of three Trichogramma (Hymenoptera: Trichogrammatidae) species reared on Trichoplusia ni (Lepidoptera: Noctuidae) eggs. J Insect Sci 15:1-6

Luna MG, Sanchez NE, Pereyra PC, Nieves E, Savino V, Luft E, Virla E, Speranza S (2012) Biological control of Tuta absoluta in Argentina and Italy: evaluation of indigenous insects as natural enemies. European Medit PI Prot Org Bull 42: $260-267$

Maia N, De HA, Luiz AJB, Campanhola C (2000) Statistical inference on associated fertility, life table parameters using jackknife technique: computational aspects. J Econ Entomol 93:11-518

Noldus LPJJ (1989) Semiochemicals, foraging behavior and quality of entomophagous insects for biological control. J Appl Entomol 108:425-451

Ozder N, Kara G (2010) Comparative biology and life tables of Trichogramma cacoeciae, T. brassicae and T. evanescens (Hymenoptera: Trichogrammatidae) 
with Ephestia kuehniella and Cadra cautella (Lepidoptera: Pyralidae) as hosts at three constant temperatures. JBiocont Sci Technol 20:245-255

Perveen F, Sultan R, Haque EU (2012) Role of temperature and hosts (Sitotroga cerealellaand Corcyra cephalonica) egg age on the quality production of Trichogramma chilonis. Arthropods 1:144-150

Pratissoli D (1995) Bioecologia de Trichogramma pretiosum Riley, 1879, nas traceas, Scrobipalpuloides absoluta (Meyrick, 1917) Phthorimaea operculella (Zeller, 1873), em tomateiro. Doutorado Escola Superior de Agricultura Luiz de Queiroz, Piracicaba, p 153

Pratissoli D, Fernandes OA, Zanuncio JC, Pastori PL (2004a) Fertility life table of Trichogramma pretiosum and Trichogramma acacioi (Hymenoptera: Trichogrammatidae) on Sitotroga cerealella (Lepidoptera: Gelechiidae) eggs at different constant temperatures. An Entomol Soc Am 97:729-731

Pratissoli D, Parra JRP (2000) Fertility life table of Trichogramma Pretiosum (Hym., Trichogrammatidae) in eggs of Tuta absoluta and Phthorimaea operculella(Lep. Gelechiidae) at different temperatures. J Appl Entomol 124:339-342

Pratissoli D, Zanuncio JC, Vianna UR, Andrade JDS, Guimaraes EM, Espindula MC (2004b) Fertility life table of Trichogramma pretiosum andTrichogramma acacioi (Hymenoptera: Trichogrammatidae) onAnagasta kuehniella; eggs at different constant temperatures. Pesquisa Agropecuaria Brasileira 39:31-35

Puneeth P, Vijayan VA (2014) Parasitization capacity of Trichogramma chilonis Ishii (Hymenoptera: Trichogrammatidae) on the eggs of Helicoverpa armigera (Lepidoptera: Noctuidae) under laboratory conditions. Int I Sci Nat 5:462-465

Qiu B, Zhou Z, Xu Z (2013) Age preference and fitness of Microplitis manila (Hymenoptera: Braconidae) reared on Spodoptera exigua (Lepidoptera: Noctuidae). Florida Entomol 96:602-609

Sharma PL, Gavkare O (2017) New distributional and record of invasive pest, T. absoluta (Meyrick) in North Western Himalayan region of India. Nat Acad Sci Lett 40:217-220

Sheoran OP, Tonk DS, Kaushik LS, Hasija RC, Pannu RS (1998) Statistical software package for agricultural research workers. In: Hooda DS, Hasija RC (eds) Recent advances in information theory, statistics \& computer applications. Department of Mathematics Statistics, CCS HAU, Hisar, pp 139-143

Sridhar V, Chakravarthy AK, Asokan R, Vinesh LS, Rebijith KB, Vennila S (2014) New records of invasive South American tomato leaf miner, Tuta absoluta (Meyrick) (Lepidoptera: Gelechiidae) in India. Pest Manag Hortic Ecos 20:148-154

Urbaneja AR, Vercher V, Navarro F, Mari G, Porcuna JL (2008) La polilla del tomato, Tuta absoluta. Phytoma Espana 194:16-23

van Lenteren J (2012) IOBC internet book of biological control. Version6. (http:// www.iobcglobal.org/download/IOBC_InternetBookBiCoVersion6Spring2012. pdf) (accessed on 20 Jan 2016)

van Lenteren JC (1986) Parasitoids in the greenhouse: successes with seasonal inoculative release systems. In: Waage J, Greathead D (eds) Insect parasitoids. Academic Press, London, p 341-374

Vigneswaran S, Jethva DM, Wadaskar PS, Balas TK (2017) Effect of cold temperature durations on the emergence and parasitization efficiency of laboratory reared Trichogramma chilonis (Ishii). Int J Curr Microbiol Appl Sci 6:1191-1199

Zappala L, Bernardo U, Biondi A, Cocco A, Deliperi S (2012) Recruitment of native parasitoids by the exotic pest Tuta absoluta (Meyrick) in Southern Italy. Bull Insectol 65:51-61

\section{Submit your manuscript to a SpringerOpen ${ }^{\circ}$ journal and benefit from:}

- Convenient online submission

- Rigorous peer review

- Open access: articles freely available online

- High visibility within the field

- Retaining the copyright to your article

Submit your next manuscript at $\boldsymbol{\nabla}$ springeropen.com 